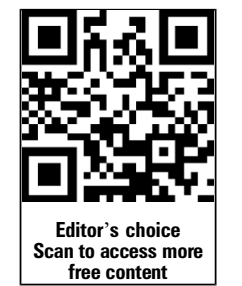

free content
- Additional material is published online only. To view please visit the journal online (http://dx.doi.org/10.1136/ bjophthalmol-2013-304485).

${ }^{1}$ West of England Eye Unit, Royal Devon and Exeter NHS Foundation Trust, Exeter, Devon, UK

${ }^{2}$ Department of Ophthalmology, Wirral University Teaching Hospital NHS Foundation Trust, Arrowe Park Hospital, Wirral, Merseyside, UK

${ }^{3}$ School of Computing and Mathematics, Plymouth University, Exeter, Devon, UK

\section{Correspondence to} Jonathan C Park, West of England Eye Unit, Royal Devon and Exeter NHS Foundation Trust, Exeter, Devon EX2 5DW UK; jonathanpark@nhs.net

Work relating to this project has been presented in part at the British and Eire Association of Vitreo-Retinal Surgeons (BEAVRS) annual meeting (2009, 2010, 2011, 2012), Royal College of

Ophthalmologists annual congress $(2010,2011,2012$ and 2013) and at the American Society of Retinal Surgery annual meeting (2012 and 2013).

Received 15 October 2013 Revised 3 December 2013 Accepted 18 December 2013 Published Online First 13 January 2014

\section{CrossMark}

\begin{tabular}{l}
\hline To cite: Park JC, \\
Ramasamy B, Shaw S, et al. \\
Br J Ophthalmol \\
2014;98:529-533.
\end{tabular}

\title{
A prospective and nationwide study investigating endophthalmitis following pars plana vitrectomy: incidence and risk factors
}

\author{
Jonathan C Park, ${ }_{1}^{1}$ Balasubramanian Ramasamy, ${ }^{2}$ Stephen Shaw, ${ }^{3}$ Som Prasad, ${ }^{2}$ \\ Roland $\mathrm{H}$ L Ling ${ }^{1}$
}

ABSTRACT

Background/aims This is the first nationwide prospective study to investigate the incidence and risk factors of endophthalmitis following pars plana vitrectomy (PPV).

Methods This was a prospective, nationwide casecontrol study. Cases of presumed infectious endophthalmitis within 6 weeks of PPV were reported via the established British Ophthalmological Surveillance Unit. The surveillance period was 2 years. Controls (patients who had PPV but no endophthalmitis) were recruited from nine randomly selected UK centres.

Results 37 reports were received and 28 cases met the diagnostic criteria for presumed infectious endophthalmitis following PPV. The incidence of endophthalmitis following PPV was 28 cases per 48433 PPVs ( 1 in 1730 with a $95 \% \mathrm{Cl}$ of 1 in 1263 to 1 in 2747). 272 controls were randomly recruited from nine UK centres. Smaller gauge port sizes were not found to be a risk. Immunosuppression (OR 19.0, $p=0.001$ ) and preoperative topical steroids (OR $131.4, p<0.001)$ increased the endophthalmitis risk. Operating for retinal detachment was associated with a reduced risk of endophthalmitis (OR 0.10, $p=0.005$ ).

Conclusions Endophthalmitis following PPV is rare. Operating with smaller gauge port sizes does not increase the risk of endophthalmitis.

\section{INTRODUCTION}

Endophthalmitis is a devastating intraocular infection that poses a high risk of severe visual loss. As with any intraocular intervention, pars plana vitrectomy (PPV) carries a risk of endophthalmitis. For cataract surgery, the risk of endophthalmitis has been thoroughly investigated by prospective studies, ${ }^{12}$ but studies on the risk of endophthalmitis following PPV are retrospective, have small sample sizes and potential geographical bias. ${ }^{3-16}$

These retrospective studies reported conflicting results regarding the incidence of endophthalmitis in transconjunctival sutureless vitrectomy (TSV) with either 23-gauge (23G) or 25-gauge (25G) surgery, relative to the conventional, sutured 20-gauge (20G) surgery. Some studies reported a significantly increased incidence of endophthalmitis in TSV, ${ }^{8}{ }^{10}{ }^{11}$ while others suggested no increase in incidence of endophthalmitis in TSV. ${ }^{3-7} 9$ It is plausible that evolving incision techniques and technology for TSV have led to a change in endophthalmitis incidence, which may explain the difference in incidence of endophthalmitis between earlier and more recent series.

Surgeons now routinely use TSV and this shift towards TSV is increasing in the UK and USA. ${ }^{17}$
Because of conflicting retrospective data and concerns surrounding TSV we thought it imperative to obtain more robust data relating to endophthalmitis following PPV.

This is the first prospective and nationwide study to investigate endophthalmitis following PPV. We aimed to establish the incidence and risk factors for presumed infectious endophthalmitis following PPV in the UK.

\section{MATERIALS AND METHODS}

We conducted a prospective, nationwide casecontrol study through the surveillance network provided by the British Ophthalmological Surveillance Unit (BOSU) over a 2-year period (1 May 2010 to 1 May 2012). BOSU provides an established infrastructure to prospectively investigate ophthalmic conditions with important public health implications in the UK. ${ }^{18}$

All independent UK Ophthalmologists were sent a monthly report card to report any case of presumed infectious endophthalmitis following PPV during the surveillance period. The case definition was 'any case that was diagnosed and managed as having infectious endophthalmitis within 6 weeks of PPV, regardless of microbiology culture status'. PPV performed for dropped nuclear fragment after complicated cataract surgery, open-globe trauma, intraocular foreign body and endophthalmitis were excluded.

Ophthalmologists reporting cases of endophthalmitis following PPV were sent an initial questionnaire within 2 weeks and a follow-up questionnaire 6 months later to obtain case information (questionnaires available as supplemental data/web only files). This included potential systemic and ocular risk factors, preoperative clinical features, operative details and perioperative complications as shown in table 1. Information relating to endophthalmitis clinical presentation, management and outcome are reported elsewhere. ${ }^{19}$

Nine UK vitreoretinal centres were randomly selected as control centres. Each control centre was asked to provide control data on at least 30 patients who had PPV without postoperative endophthalmitis during the same study period. This yielded a total of 272 controls.

The nine control centres were also asked to participate as validation centres by providing 'in-house' data on cases of endophthalmitis following PPV during the study period. This information was obtained by the review of adverse event recordings and critical incidence reports. This information was compared with the number of 
Table 1 Comparing cases with controls with initial univariate analysis to suggest possible risk factors for endophthalmitis following vitrectomy

\begin{tabular}{|c|c|c|c|}
\hline Variable (potential risk factor) & Cases (total $n=28$ ) & Controls (total $n=272$ ) & p Value \\
\hline Age & Median average age 61 & Median average age 63 & $0.95^{*}$ \\
\hline Gender (male sex) & $67 \%$ & $50 \%$ & $0.07 \dagger$ \\
\hline Diabetes mellitus & 9/27 (33.3\%) & $51 / 268(19.0 \%)$ & $0.078+$ \\
\hline Immunosuppression & $3 / 25(12.0 \%)$ & $5 / 267(1.9 \%)$ & $0.023 \ddagger$ \\
\hline Preop oral steroid use & $2 / 27(7.4 \%)$ & $2 / 267(0.7 \%)$ & $0.043 \ddagger$ \\
\hline Preop topical steroid use & $12 / 27(44.4 \%)$ & $4 / 267(1.5 \%)$ & $<0.001 \ddagger$ \\
\hline Recent intraocular surgery & $6 / 21(28.6 \%)$ & $8 / 270(3.0 \%)$ & $<0.001 \dagger$ \\
\hline Lens status (phakic) & $15 / 27(55.6 \%)$ & $190 / 269(70.6 \%)$ & $0.11 \dagger$ \\
\hline Previous glaucoma filtration surgery & $2 / 27(7.4 \%)$ & $0 / 267(0 \%)$ & $0.008 \ddagger$ \\
\hline Surgeon grade (non-consultant) & $5 / 27(18.5 \%)$ & $78 / 270(28.9 \%)$ & $0.25 t$ \\
\hline Port size $(23 \mathrm{G}$ or $25 \mathrm{G})$ & $18 / 28(64.3 \%) \S$ & $104 / 265(39.2 \%)$ & $0.011 \dagger$ \\
\hline One or more ports sutured & $16 / 26(61.5 \%)$ & $205 / 255(80.4 \%)$ & $0.025 t$ \\
\hline Conjunctiva displaced & $14 / 17(82.4 \%)$ & $68 / 84(81.0 \%)$ & $0.89+$ \\
\hline Subconjunctival antibiotic & $26 / 27(96.3 \%)$ & $255 / 271(94.1 \%)$ & $0.64 t$ \\
\hline Intra-cameral or intra-vitreal antibiotic & $1 / 27(3.7 \%)$ & $7 / 271(2.6 \%)$ & $0.73+$ \\
\hline Postoperative hypotony & $0 / 27(0 \%)$ & $2 / 271(0.7 \%)$ & $0.65 t$ \\
\hline Postoperative wound leak & $0 / 27(0 \%)$ & $0 / 271(0 \%)$ & $\mathrm{n} / \mathrm{a}$ \\
\hline Retinal detachment & $6 / 27(22.2 \%)$ & $132 / 271(48.7 \%)$ & $0.015 t$ \\
\hline Macular hole & $2 / 27(7.4 \%)$ & $45 / 271(16.6 \%)$ & $0.28 \ddagger$ \\
\hline Epi-retinal membrane & $8 / 27(29.6 \%)$ & $40 / 271(14.8 \%)$ & $0.055 \ddagger$ \\
\hline Diabetic vitreous haemorrhage & $6 / 27(22.2 \%)$ & $19 / 271(7.0 \%)$ & $0.017 t$ \\
\hline Non-diabetic vitreous haemorrhage & $2 / 27(7.4 \%)$ & $12 / 271(4.4 \%)$ & $0.37 \ddagger$ \\
\hline Diabetic delamination & $3 / 27(11.1 \%)$ & $14 / 271(5.2 \%)$ & $0.19 \ddagger$ \\
\hline Vitreo-macular traction syndrome & $4 / 27(14.8 \%)$ & $7 / 271(2.6 \%)$ & $0.011 \ddagger$ \\
\hline Vitreous opacity & $2 / 27(7.4 \%)$ & $3 / 271(1.1 \%)$ & $0.067 \ddagger$ \\
\hline Other indication for vitrectomy & $2 / 27(7.4 \%)$ & $7 / 271(2.6 \%)$ & $0.052 \ddagger$ \\
\hline
\end{tabular}

cases that had been reported to BOSU to estimate under-reporting.

The incidence of endophthalmitis was calculated based on the number of reported cases that met the diagnostic criteria divided by the number of PPVs performed in the UK by the National Health Service (NHS) and private sectors, based on hospital episode and statistics (HES) data ${ }^{20}$ and UK census data. ${ }^{21}$

Cases were compared with controls with univariate analysis to suggest possible risk factors for endophthalmitis following PPV. $\chi^{2}$ tests or Fisher's exact tests were used for categorical variables and average age was compared using a Mann-Whitney test. Possible risk factors from this analysis (all with a $\mathrm{p}$ value of less than 0.1 ) were then included in binary logistic regression (forward likelihood ratio method) to establish if multivariate analysis could identify independent risk factors for endophthalmitis following PPV. ORs and 95\% CIs were calculated for risk factors which were significant (at $\mathrm{p}<0.05)$ in the logistic regression.

The study received ethical approval from the South West Multicentre Research and Ethics Committee. The study was recognised as a National Institute for Health Research portfolio study and all centres involved were registered on the integrated research application system.

\section{RESULTS}

\section{Numbers of cases and controls}

Thirty-seven cases of presumed infectious endophthalmitis occurring within 6 weeks of PPV were reported to the study group during the 2-year surveillance period (1 May 2010 to 1 May 2012). Five were PPVs for dropped nuclear fragment after complicated cataract surgery, three were duplicate reports and no information could be obtained for one case. Therefore, a total of 28 cases met the inclusion criteria.

From the nine control centres, control data were available from a total of 272 patients (32 from one centre and 30 from each of the other centres). The same centres acting as validation centres reported no cases of endophthalmitis following PPV in seven centres, and two centres had one case each. Both of these cases of endophthalmitis had already been reported to BOSU. The reporting rate among validation centres was therefore $100 \%$.

\section{Incidence of endophthalmitis following vitrectomy}

The nationwide incidence of endophthalmitis following PPV is the number of cases (numerator) divided by the number of PPV operations (denominator) performed in the UK in the same period.

Twenty-eight cases met the inclusion criteria during the study period and form the numerator. A total of 38164 PPVs were performed in England during the study period according to HES data (18 646 for 2009-2010 and 19518 for 2010-2011). These HES data reflect NHS operations in England only. The 2011 Census from the Office of National Statistics shows that $84 \%$ of the UK population lives in England. ${ }^{21}$ Extrapolating HES data to the UK population would estimate a total of 
Table 2 Comparing cases with controls with subsequent multivariate analysis (logistic regression) to identify risk factors for endophthalmitis following vitrectomy

\begin{tabular}{lrcc}
\hline Variable (potential risk factor) & $\mathbf{p}$ Value & OR if $\mathbf{p}<\mathbf{0 . 0 5}$ & $\begin{array}{l}\mathbf{9 5 \%} \mathrm{CI} \text { for } \mathrm{OR} \\
\mathbf{p}<\mathbf{0 . 0 5}\end{array}$ \\
\hline Immunosuppression & 0.001 & 19.0 & 3.1 to 115.7 \\
Preop topical steroid use & $<0.001$ & 131.4 & 21.8 to 792.7 \\
Retinal detachment & 0.005 & 0.10 & 0.02 to 0.50 \\
\hline
\end{tabular}

45433 PPVs performed by the NHS in the UK during the study period.

Although the number of NHS PPVs greatly exceeds that of private PPVs, we included private sector PPVs for completeness. One case of endophthalmitis reported followed private PPV. The number of private PPVs was estimated to be 3000 during the study's surveillance period (according to the private sales of various companies combined with their market share according to data on file).

Therefore, during the study's 2-year surveillance period we estimate a total of 48433 PPVs were done in the UK (NHS and private operations). This suggests the incidence to be 28 per 48433 ( 1 in 1730 or $0.058 \%$; with a $95 \%$ CI of 1 in 1263 to 1 in 2747).

\section{Risk factors for endophthalmitis following vitrectomy}

Demographics comparison between cases and controls did not show a significant difference (table 1).

Univariate analysis comparing cases with controls was completed and suggested the following as possible risk factors for endophthalmitis: immunosuppression, preoperative topical steroid use, preoperative oral steroid use, recent intraocular surgery, previous glaucoma filtration surgery, port size, suturing one or more ports and diabetic vitreous haemorrhage (table 1). These possible risk factors were then analysed with multivariate analysis (logistic regression), which identified independent variables as risk factors for endophthalmitis (table 2).

Two independent risk factors were therefore identified for endophthalmitis, which were immunosuppression (OR 19.0, 95\% CI 3.1 to $115.7, \mathrm{p}=0.001)$ and preoperative topical steroid use (OR 131.4, 95\% CI 21.8 to $792.7, \mathrm{p}<0.001$ ). Operating with smaller ports $(23 \mathrm{G}$ or $25 \mathrm{G})$ was not a risk factor relative to $20 \mathrm{G}(\mathrm{p}=0.96)$. Operating for retinal detachment was associated with a reduced risk of endophthalmitis (OR $0.10,95 \%$ CI 0.02 to $0.50, \mathrm{p}=0.005$ ).

\section{DISCUSSION}

This is the first nationwide prospective study to investigate endophthalmitis following PPV. Previous studies have been retrospective, related to a small geographical area and only acquired a small number of cases. ${ }^{3-16}$ This study has the advantage of being prospective and therefore more resistant to bias, under-reporting, poor follow-up and other confounding factors. Utilising the BOSU infrastructure, we had a larger study population (the entire UK), which yielded more cases than previous studies (table 3). The number of cases of endophthalmitis in this study (28 cases) is similar to the landmark European Society of Cataract and Refractive Surgeons' study investigating endophthalmitis following cataract surgery (29 cases). ${ }^{1}$

A disadvantage of our study is the possibility of underreporting, although this is likely to be lower than retrospective studies. BOSU has been established for over a decade and reporting rates are typically reasonable and estimated to be $70 \% .{ }^{18}$ In addition to the monthly reminder from BOSU to all independent UK Ophthalmologists, vitreo-retinal surgeons were regularly reminded to report cases at the British and Eire Association of Vitreo-Retinal Surgeons (BEAVRS) annual meetings in 2009, 2010, 2011 and 2012, via the BEAVRS online forum and by presentations at The Royal College of Ophthalmologists Retina day (2009-1012). Three duplicate reports are reassuring in that they support the likelihood of a high reporting rate. This was supported by the $100 \%$ reporting rate for the validation centres. The estimated incidence of endophthalmitis following PPV is therefore a minimum incidence, since the effect of possible under-reporting would result in cases being more common than this figure would suggest.

Our study's estimate of the minimum incidence of endophthalmitis following PPV is 28 per 48433 (1 in 1730 with a 95\% CI of 1 in 1263 to 1 in 2747). Table 3 compares this incidence to other studies. This study suggests endophthalmitis is more common than recent retrospective studies, ${ }^{3-7} 9$ which is not surprising given the potential for under-reporting in retrospective studies. Similarly, large, robust prospective studies investigating endophthalmitis following cataract surgery ${ }^{1}$ found higher rates of endophthalmitis relative to smaller retrospective studies. Our estimate is however less common than the retrospective studies, finding surprisingly high rates of endophthalmitis during the introduction of TSV when such surgery was relatively novel. ${ }^{8} 1011$ This perhaps reflects evolution of a safer technique as the learning curve with TSV has plateaued, such as ensuring conjunctival displacement prior to TSV port insertion, construction of a stepped or oblique wound and placement of suture if there is any concern of wound leak.

A very important negative finding of this study is that operating with TSV, relative to conventional 20G surgery, does not increase the risk of endophthalmitis. Previous retrospective and smaller studies have reported conflicting results regarding TSV as a possible risk factor for endophthalmitis. Some of these retrospective studies have found TSV to be a risk ${ }^{8} 1011$ and others have not found TSV to be a risk for endophthalmitis following PPV. ${ }^{3-7} 9$ Our prospective study is relatively robust and we observed no increased risk of endophthalmitis following PPV with TSV.

No cases in this study had clinically demonstrable hypotony or wound leak on the first postoperative day or at the time of endophthalmitis diagnosis. This does not exclude subclinical hypotony or wound leak occurring immediately postoperatively which has previously been postulated to be a risk factor for endophthalmitis with TSV, since human cadaveric eyes demonstrate that ocular surface fluid is more likely to enter the vitreous cavity through TSV $(23 \mathrm{G}$ or $25 \mathrm{G}$ ) sclerotomies relative to 20G sutured sclerotomies. ${ }^{22}$ The rate of suturing one or more ports in this study may appear surprisingly high (since 23G and 25G are typically considered 'sutureless') for cases and controls (table 2). However, the suture rate in this study is not that dissimilar to the suture rate reported by the American Society of Retina Specialists 2012 survey $^{23}$ (approximately 40\%) and that reported by the UK BEAVRS 2012 survey $^{24}$ (where approximately $40 \%$ of surgeons sutured at least one port for more than $25 \%$ of their cases). Our study found that suturing ports did not affect the risk of endophthalmitis following PPV (table 3).

Immunosuppression increased the risk of endophthalmitis. The three cases that were immunosuppressed had lymphoma, inflammatory bowel disease requiring immunosuppression and end stage renal failure. Diabetes mellitus was not found to be a risk factor for endophthalmitis following PPV. 
Table 3 Previous studies estimating the incidence of endophthalmitis following pars plana vitrectomy

\begin{tabular}{|c|c|c|}
\hline Study & Absolute number of cases of endophthalmitis & Incidence of endophthalmitis \\
\hline Park et al, 2013 (this article) & $\begin{array}{l}28 \text { per } 48433 \\
(10 \text { were } 20 \mathrm{G}, 17 \text { were } 23 \mathrm{G} \text { and } 1 \text { was } 25 \mathrm{G} \text { ) }\end{array}$ & $\begin{array}{l}1 \text { in } 1730 \\
0.058 \% \\
(95 \% \mathrm{Cl}, 1 \text { in } 1263 \text { to } 1 \text { in } 2747)\end{array}$ \\
\hline Wu et $a l^{3}$ & $\begin{array}{l}1 \text { per } 4717(25 \mathrm{G}) \\
3 \text { per } 10845(23 \mathrm{G}) \\
4 \text { per } 19865(20 \mathrm{G})\end{array}$ & $\begin{array}{l}1 \text { in } 4717 ; 0.021 \%(25 \mathrm{G}) \\
1 \text { in } 3615 ; 0.028 \%(23 \mathrm{G}) \\
1 \text { in } 4966 ; 0.020 \%(20 \mathrm{G})\end{array}$ \\
\hline Scott et $a l^{4}$ & $\begin{array}{l}1 \text { per } 789(25 G) \\
1 \text { per } 3362(23 G) \\
1 \text { per } 4403(20 G)\end{array}$ & $\begin{array}{l}1 \text { in } 789 ; 0.127 \%(25 G) \\
1 \text { in } 3362 ; 0.030 \%(23 G) \\
1 \text { in } 4403 ; 0.023 \%(20 G)\end{array}$ \\
\hline Parolini et a $\left.\right|^{5}$ & $\begin{array}{l}0 \text { in } 943(23 G) \\
1 \text { in } 3078(20 G)\end{array}$ & 1 in $3078 ; 0.032 \%(20 \mathrm{G})$ \\
\hline Hu et al ${ }^{6}$ & $\begin{array}{l}1 \text { per } 1424(25 \mathrm{G}) \\
0 \text { per } 1948(20 \mathrm{G})\end{array}$ & 1 in $1424 ; 0.070 \%(25 G)$ \\
\hline Chen et $a l^{7}$ & $\begin{array}{l}1 \text { per } 431(25 G) \\
1 \text { per } 3046(20 G)\end{array}$ & $\begin{array}{l}1 \text { in } 431 ; 0.232 \%(25 G) \\
1 \text { in } 3046 ; 0.033 \%(20 G)\end{array}$ \\
\hline Scott et al ${ }^{8}$ & $\begin{array}{l}11 \text { per } 1307(25 G) \\
2 \text { per } 6375(20 G)\end{array}$ & $\begin{array}{l}1 \text { in } 119 ; 0.840 \%(25 \mathrm{G}) \\
1 \text { in } 3188 ; 0.031 \%(20 \mathrm{G})\end{array}$ \\
\hline Shimada et $a l^{9}$ & $\begin{array}{l}1 \text { per } 3343(25 G) \\
1 \text { per } 3592(20 G)\end{array}$ & $\begin{array}{l}1 \text { in } 3343 ; 0.030 \%(25 G) \\
1 \text { in } 3592 ; 0.028 \%(20 G)\end{array}$ \\
\hline Kunimoto and Kaiser ${ }^{10}$ & $\begin{array}{l}7 \text { per } 3103(25 \mathrm{G}) \\
1 \text { per } 5498(20 \mathrm{G})\end{array}$ & $\begin{array}{l}1 \text { in } 443 ; 0.226 \%(25 G) \\
1 \text { in } 5498 ; 0.018 \%(20 G)\end{array}$ \\
\hline Shaikh et al ${ }^{11}$ & $\begin{array}{l}2 \text { per } 129(25 \mathrm{G}) \\
0 \text { per } 129(20 \mathrm{G})\end{array}$ & 1 in $65 ; 1.538 \%(25 G)$ \\
\hline Joondeph et a/ ${ }^{12}$ & 5 per 10397 & $\begin{array}{l}1 \text { in } 2080 \\
0.048 \%\end{array}$ \\
\hline Eifrig et $a l^{13}$ & 6 per 15326 & $\begin{array}{l}1 \text { in } 2554 \\
0.039 \%\end{array}$ \\
\hline Aaberg et $a l^{14}$ & 3 per 6557 & $\begin{array}{l}1 \text { in } 2186 \\
0.046 \%\end{array}$ \\
\hline Cohen et $a l^{15}$ & 18 cases; incidence based on 9 per 12216 & $\begin{array}{l}1 \text { in } 1357 \\
0.074 \%\end{array}$ \\
\hline Ho and Tolentino ${ }^{16}$ & 4 per 2817 & $\begin{array}{l}1 \text { in } 704 \\
0.142 \%\end{array}$ \\
\hline
\end{tabular}

Vitrectomies were for $20 \mathrm{G}$ unless otherwise stated.

Preoperative topical steroids increased the risk of endophthalmitis. Subgroup analysis demonstrates this is an independent risk factor and other potential confounding factors are not responsible (such as recent surgery or uveitis which are common causes for necessitating preoperative topical steroids). Topical steroids in the short term do not increase conjunctival bacterial flora counts, ${ }^{25}$ but topical steroids do reduce the function of leucocytes to oppose infection so we speculate that preoperative topical steroids may locally immunocompromise the eye and hence increase the risk of endophthalmitis.

PPV performed for retinal detachment was associated with a reduced risk of endophthalmitis. PPV for retinal detachment typically have an endotamponade whereas PPV for other indications are less likely to have an endotamponade (such as epiretinal membrane and vitreous haemorrhage). It has previously been speculated that endotamponades may reduce the risk of endophthalmitis by reducing hypotony and improving wound integrity. ${ }^{6}$ This may explain why retinal detachment as an indication for PPV was associated with a reduced risk of endophthalmitis.

In summary, the incidence of endophthalmitis following PPV in the UK is rare. This study has provided a robust estimate for the incidence of endophthalmitis following PPV, which surgeons can use as a benchmark for their own practice and as information for patient consent. Surgeons and patients should be aware that operating in patients who are immunocompromised or who are taking preoperative topical steroids are at a higher risk of endophthalmitis following PPV. Operating with smaller gauge port sizes does not increase the risk of endophthalmitis.

Acknowledgements The study group would like to thank the Fight for Sight charity for their financial support; Dr Barny Foot (and the BOSU) for facilitating the study throughout its course; Mrs Judith Belam and Mrs Melanie Hutchings (Royal Devon and Exeter Hospital NHS Foundation Trust) for administrative support. We would also like to thank the following Ophthalmologists who helped provide control and validation data: Mr Kwabena Frimpong-Ansah, Mr Vasant Raman (Plymouth Royal Eye Infirmary), Mr Eddie Doyle, Mr Charlie James, Mr Mick Cole, Mr Will Sheehan (South Devon NHS Foundation Trust), Mr Steve Charles, Dr Whye-On Ho (Manchester Royal Eye Infirmary), Mr David Yorston, Mr Amer Awan (Gartnavel Hospital), Prof Rob MacLaren, Mr CK Patel, Mr Paul Rosen, Dr Emily Fletcher (Oxford Eye Hospital), Mr Luke Membrey, Mr Nick Muthiah (Maidstone Hospital), Mr Nick Price, Mr Kostas Chalioulias (Wolverhampton Hospital), Mr Ishtiyak Mahomed, Mr Gurpal Toor (Bradford Hospital), Mr Somnath Banerjee, Mr S Ganesh (University of Leicester Hospital), Mr Eric Ezra (Moorfields Eye Hospital). We would also like to thank those Ophthalmologists who kindly reported cases to us.

Collaborators Barny Foot; Judith Belam; Melanie Hutchings; Kwabena Frimpong-Ansah; Vasant Raman; Eddie Doyle; Charlie James; Mick Cole; Will Sheehan; Steve Charles; Whye-On Ho; David Yorston; Amer Awan; Rob MacLaren; CK Patel; Paul Rosen; Emily Fletcher; Luke Membrey; Nick Muthiah; Nick Price; Kostas Chalioulias; Ishtiyak Mahomed; Gurpal Toor; Somnath Banerjee; S Ganesh; Eric Ezra.

Contributors All of the authors have made substantial contributions to the conception and design, acquisition of data, or analysis and interpretation of data; drafted the article or revised it critically for important intellectual content; and given final approval of the version to be published. 
Funding The study group received funding from the Fight for Sight charity awarded via the Royal College of Ophthalmologists' BOSU and from research funds from the Royal Devon and Exeter NHS Foundation Trust and Wirral University Teaching Hospital NHS Foundation Trust.

Competing interests RHLL has received sponsorships from Novartis and Allergan for attending conferences.

Ethics approval South West Multi-Centre Research and Ethical Board.

Provenance and peer review Not commissioned; externally peer reviewed.

Data sharing statement Further data are available from the corresponding author.

\section{REFERENCES}

1 ESCRS Endophthalmitis Study Group. Prophylaxis of postoperative endophthalmitis following cataract surgery: results of the ESCRS multi-center study and identification of risk factors. J Cataract Ref Surg 2007;33:978-88.

2 Kamalarajah S, Ling R, Silvestri G, et al. Presumed infectious endophthalmitis following cataract surgery in the UK: a case-control study of risk factors. Eye 2007;21:580-6.

3 Wu L, Berrocal MH, Arevalo JF, et al. Endophthalmitis after pars plana vitrectomy. Results of the Pan American Collaborative Retina Study Group. Retina 2011;31:673-78.

4 Scott IU, Flynn HW Jr, Acar N, et al. Incidence of endophthalmitis after 20-gauge vs 23 -gauge vs 25 -gauge pars plana vitrectomy. Graefes Arch Clin Exp Ophthalmol 2011;249:377-80.

5 Parolini B, Romanelli F, Prigione G, et al. Incidence of endophthalmitis in a large series of 23-gauge and 20-gauge transconjunctival pars plana vitrectomy. Graefes Arch Clin Exp Ophthalmol 2009:247:895-98.

$6 \mathrm{Hu}$ AYH, Bourges JL, Shah SP, et al. Endophthalmitis after pars plana vitrectomy. Ophthalmology 2009;116:1360-65.

7 Chen JK, Khurana RN, Nguyen QD, et al. The incidence of endophthalmitis following transconjunctival sutureless 25 vs 20 gauge vitrectomy. Eye 2009;23:780-84.

8 Scott IU, Flynn HW, Dev S, et al. Endophthalmitis after 25 gauge and 20 gauge pars plana vitrectomy: incidence and outcomes. Retina 2008:28:138-42.

9 Shimada $H$, Nakashizuka $H$, Hattori $T$, et al. Incidence of endophthalmitis after 20 and 25 gauge vitrectomy: causes and prevention. Ophthalmology 2008;115:2215-20.
10 Kunimoto DY, Kaiser RS. Incidence of endophthalmitis after 20 and 25 gauge vitrectomy. Ophthalmology 2007;112:2133-37.

11 Shaikh S, Ho S, Richmond PP, et al. Untoward outcomes in 25-gauge versus 20-gauge vitreoretinal surgery. Retina 2007;27:1048-53.

12 Joondeph BC, Blanc JP, Polkinghorne PJ. Endophthalmitis after pars plana vitrectomy: a New Zealand experience. Retina 2005;25:587-89.

13 Eifrig CW, Scott IU, Flynn HW Jr, et al. Endophthalmitis after pars plana vitrectomy: incidence, causative organisms, and visual acuity outcomes. Am J Ophthalmol 2004; 138:799-802.

14 Aaberg TM Jr, Flynn HW Jr, Schiffman J, et al. Nosocomial acute-onset postoperative endophthalmitis survey. Ophthalmology 1998;105:1004-10.

15 Cohen SM, Flynn HW Jr, Murray TG, et al. Endophthalmitis after pars plana vitrectomy. The Post Vitrectomy Endophthalmitis Study Group. Ophthalmology 1995;102:702-12.

16 Ho PC, Tolentino FI. Bacterial endophthalmitis after closed vitrectomy. Arch Ophthalmol 1984;102:207-10

17 Park JC, Ramasamy B, Ling RHL, et al. A review of endophthalmitis following vitrectomy. Expert Rev Ophthalmol 2012;7:227-40.

18 Foot B, Stanford M, Rahi J, et al. The British Ophthalmological Surveillance Unit: an evaluation of the first 3 years. Eye 2003;17:9-15.

19 Park JC, Ramasamy B, Shaw S, et al. A prospective and nationwide study investigating endophthalmitis following pars plana vitrectomy: clinical presentation, microbiology, management and outcome. $\mathrm{Br} J$ Ophthalmol submitted.

20 Hospital Episode Statistics data for England NHS operations. http://www.hesonline. nhs.uk (accessed 1 Jan 2014)

21 The Office For National Statistics, UK Census data. http://www.ons.gov.uk (accessed 1 Jan 2014)

22 Gupta OP, Maguire Jl, Eagle RC Jr, et al. The competency of pars plana vitrectomy incisions: a comparative histologic and spectrophotometric analysis. Am J Ophthalmol 2009;147:243-50.

23 American Society of Retina Specialists 2012 annual survey. http://www.asrs.org (accessed 1 Jan 2014)

24 Soni M, Prasad S. British and Eire Association of Vitreo-Retinal Surgeons (BEAVRS) annual survey 2012, presented in Dublin, November 2012.

25 Ermis SS, Aktepe OC, Inan UU, et al. Effect of topical dexamethasone and ciprofloxacin on bacterial flora of healthy conjunctiva. Eye 2004;18:249-52. 